\title{
TRANSACTION COSTS INFLUENCE ON THE STABILITY OF FINANCIAL MARKET: AGENT-BASED SIMULATION
}

\author{
Roman Šperka ${ }^{1}$, Marek Spišák ${ }^{2}$ \\ Department of Informatics, School of Business Administration in Karviná, \\ Silesian University in Opava, \\ Univerzitní náměstí 1934/3, 73340 Karviná, Czech Republic \\ E-mails: ${ }^{1}$ sperka@opf.slu.cz (corresponding author); ${ }^{2}$ spisak@opf.slu.cz
}

Received 09 November 2011; accepted 06 June 2012

\begin{abstract}
We implement an agent-based simulation of financial market model. Agentbased simulations are used nowadays as an alternative to the traditional models, based on predetermined equilibrium state theory. Agent technology brings some kind of local intelligence and rational expectations to the decision support system of financial market participants. Agents follow technical and fundamental trading rules to determine their speculative investment positions. We consider direct interactions between speculators and they may decide to change their trading behaviour. If a technical trader meets a fundamental trader and they realize that fundamental trading has been more profitable than technical trading in recent past, the probability that the technical trader switches to the fundamental trading rules is relatively high. In particular the influence of transaction costs is studied in this paper. Transaction costs can be increased by the off-market regulation (for example in the form of taxes) on financial market stability, by overall volume of trade and other market characteristics. The paper shows a positive impact of suitable transaction costs on the financial market stability in the long run.
\end{abstract}

Keywords: agent-based, financial market, NetLogo, direct interactions, technical and fundamental analysis, simulation, Tobin tax.

Reference to this paper should be made as follows: Šperka, R.; Spišák, M. 2013. Transaction costs influence on the stability of financial market: agent-based simulation, Journal of Business Economics and Management 14(Supplement 1): S1-S12.

JEL Classification: E37, E44, C53, C63, C90.

\section{Introduction}

Simulation of financial market (Macal, North 2006) is a new fast growing research area with two primary motivations. The first is the need to provide a development platform for the ever increasing automation of financial markets. The second is the inability of traditional computational mathematics to predict the financial market patterns that result from the choices made by investors interacting in a financial market.

The financial market participants in our multi-agent model use technical and fundamental analysis to assess financial markets. Multi-agent financial market models have a strong empirical foundation (Spišák, Šperka 2011; Vymetal, Sperka 2011; Wooldridge 
2009). This paper firstly defines how financial market participants may select their trading rules, secondly describes a multi-agent model of the transaction costs influence on the stability of financial market. We used and extended the original model developed by Frank Westerhoff (Westerhoff 2009) in our research. This model recombines a number of building blocks from three known multi-agent models of financial market.

In the first model (Brock, Hommes 1997, 1998) a continuum of financial market participants endogenously chooses between different trading rules. The agents are rational in the sense that they tend to pick trading rules which have performed well in the recent past. This displays some kind of learning behaviour. The performance of the trading rules may be measured as a weighted average of past realized profits. The relative importance of the trading rules is derived via a discrete choice model. Contributions developed in this manner are often analytically tractable. Agents interact only indirectly with each other: their orders have an impact on the price formation. An agent is not directly affected by the actions of others.

In (Kirman 1991, 1993) an influential opinion formation model with interactions between a fixed number of agents was introduced. Agents may hold one of two views. In each time step, two agents may meet at random. There is a fixed probability that one agent may convince the other one to follow his opinion. In addition, there is also a small probability that an agent changes his opinion independently. A key finding of this model is that direct interactions between heterogeneous agents may lead to substantial opinion swings.

The models of (Lux 1998) and (Lux, Marchesi 1999) also focus on the case of a limited number of agents. Within this approach, an agent may either be an optimistic or a pessimistic technical trader, or a fundamental trader. The probability that agents switch from having an optimistic technical attitude to a pessimistic one (and vice versa) depends on the majority opinion among the technical traders and the current price trend. For instance, if the majority of technical traders are optimistic and if prices are going up, the probability that pessimistic technical traders turn into optimistic technical traders is relatively high. The probability that technical traders (either being optimistic or pessimistic) switch to fundamental trading (and vice versa) depends on the relative profitability of the rules.

The (Westerhoff 2009) model recombines key ingredients of the three aforementioned approaches to come with a simple model that is able to match the facts of financial markets. Direct interactions between numbers of agents are considered. To avoid asymmetric profit measures a fitness function is defined. The attractiveness of a rule is approximated by a weighted average of current and past profits. We extended this model with transaction costs influence.

The transaction costs on the financial market are mainly the costs of the obtaining and the interpreting of the information, the time required for decision making, various types of fees, etc. Transaction costs according to (Burian 2011; Ho 1998; Habermeier, Kirilenko 2003) are often viewed as negative phenomena, but there are cases where the increase in the transaction costs can be viewed positively and can contribute to the 
stability of the market. The increase in the transaction costs may also occur in the form of non-market regulation such as the taxes. In the early seventies the Nobel laureate in the economics James Tobin drafted the regulation of currency markets (Seely 2012). Tobin suggested that all short-term transactions should be taxed at a low fixed rate (the proposal was later identified as the so-called Tobin tax). The results according to Tobin would avoid short-term currency speculation and stabilize the market.

The model described here, however, needs not be interpreted as a model for the introduction of taxes, but in general, as a model of the transaction costs influence on the market stability. The aim of the model described in this paper is to explore the dependence of the market stability to the extent of transaction costs.

This paper is structured as follows. Section 1 briefly informs about the behaviour on real financial markets and introduces the agent-based methods for modelling and simulation. In section 2 the original multi-agent model of financial market is presented. In section 3 we enhance the original model with transaction costs. Section 4 presents the original simulation results of the implemented agent-based simulation.

\section{Agent-based methods for modelling and simulation of real financial markets}

The behaviour of real financial markets shows some significant deviations from the efficient-market hypothesis (Siegel 2003; Allen, Gale 2002), which argues that the market price reflects all information on the fair value of traded assets and should not deviate from it. In fact, the market price often differs from the fair value of assets, which is reflected especially in the so-called market bubbles. Market bubble is an artificial overvaluation of assets due to excessive demand, or on the other hand it is the market collapse due to the oversupply of the assets. (Burian 2011; Stein 1998; James, Smith 2000) Efficient-market hypothesis is according to (Shleifer 2000) based on three basic assumptions. Firstly the investors are able to rate the assets with unlimited rationality. Secondly if some investors are not rational, their purchases are random and therefore they cancel each other out, and finally the influence of irrational investors on the price of the assets is eliminated by rational agents.

The agent technology is widely used nowadays and not only in the finance and investment fields, but for instance in the management theory. The agent-based simulation of the company model is introduced in (Vymetal, Sperka 2011). The model presented in this paper describes some typical characteristics of the real market. A multi-agent model is a computerized simulation of a number of decision-makers (agents) and institutions, which interact through prescribed rules (Rutkauskas, Ramanauskas 2009; Shleifer 2000; Goncalves 2011). The agents can represent different financial market participants - from direct investors to the financial market supervisors and brokers - with institutions like banks and government. Multi-agent models in opposite to other models are not based on the presumption that the economy moves to the destined equilibrium state. Each agent acts at any time according to its current state, the situation of the environment around it and the conditions directing its plans. An individual investor decides whether to save 
or to invest the money according to the development of the inflation rate, his or her expectations about the future, and experiences obtained in the past. The software application stores behaviour of many agent interactions in order to analyse what happens over time. Multi-agent models and simulations can use many types of non-linear behaviour comparing with equilibrium models. Financial market supervisors can thus model and simulate an artificial economy with more policy scenarios and quantitatively measure their impacts. During the last years of the twentieth century, behavioural economics gained in importance. The theory of 'rational expectations' emerged as the dominant approach in economics. This theory implies that people have perfect access to information and adapt rationally and instantly to new situations maximizing their long-run advantage. Behavioural economics are now using topics based on the conviction that real people often act under influence of overconfidence, fear and peer pressure.

Farmer and Foley (2009) characterized the weaknesses and problems of equilibrium methods declaring that "Even if rational expectations are a reasonable model of human behaviour, the mathematical machinery is cumbersome and requires drastic simplifications to get tractable results. The equilibrium models that were developed, such as those used by the US Federal Reserve, by necessity stripped away most of the structure of a real economy. There are no banks or derivatives, much less sub-prime mortgages or credit default swaps - these introduce too much nonlinearity and complexity for equilibrium methods to handle." We agree and claim that multi-agent models could help to evaluate policies contributing to foster economic recovery.

We use agent-based methods of simulation (Situngkir, Surya 2011), (Vymetal et al. 2012), (Spisak, Sperka 2012) in the case of financial market in this paper. Financial market is a relatively balanced market (supply roughly coincides with the demand) with bubbles and busts. Furthermore, in contrast to efficient-market hypothesis assumptions is more realistic to assume that (Burian 2011; Yang 1999; Lettau 1997):

- Agents are limited only rational. They do not have all information or they are not able to interpret it correctly.

- Agents are heterogeneous. They react with varying sensitivity to the reports of the market developments. Differently strong random factors affect their decisions.

- Agents make decisions influenced by the opinions of their close colleagues.

The model described in this paper is based on these assumptions. The features of the original model used in this paper are explained in detail in the next section.

\section{Original model}

The mathematical model developed by Frank Westerhoff (Westerhoff 2009) was chosen for the implementation in this paper. It is an agent-based model simulating the financial market. Two base types of traders are represented by software agents:

- Fundamental traders - their reactions are based on the fundamental analysis. They believe that asset prices approximate their fundamental price in long term. They buy assets when the price is under the fundamental value.

- Technical traders - they decide using technical analysis. The prices tend to move in trends in their opinion. 
Price changes reflect current demand excess. This excess expresses the orders amount submitted by technical and fundamental traders each turn. The rate between their orders evolves in a time. Agents regularly meet and discuss their trading performance. One agent can be persuaded by the others to change the trading method, if his rules relative success is less than the others one. Communication is direct talk between agents. Communicating agents meet randomly - there is no special relationship between them. The success of rules is represented by current and passed profitability. The model assumes traders ability to define the fundamental value of assets. The agents' behaviour is rational.

The price reflects the relation between assets that have been bought and sold in a turn and the price change caused by these orders. This can be formalized as a simple loglinear price impact function:

$$
P_{t+1}=P_{t}+a\left(W_{t}^{C} D_{t}^{C}+W_{t}^{F} D_{t}^{F}\right)+a_{t},
$$

where $a$ is a positive price adjustment coefficient, $D^{C}$ are orders generated by technical agents while $D^{F}$ are the orders of fundamental ones. $W^{C}$ and $W^{F}$ are the weights of agents using technical respective fundamental rules. They reflect current ratio between the technical and fundamental agents. $\alpha$ brings the random term to the Eq. (1). It is an $\mathrm{IID}^{1}$ normal random variable with mean zero and constant standard deviation $\sigma^{\alpha}$.

As was already said, technical analysis extrapolates the price trends - when they go up (the price grows) agents buy the assets. So the formalization for technical order rules can be like this:

$$
D_{t}^{C}=b\left(P_{t}-P_{t-1}\right)+\beta_{t} .
$$

The parameter $b$ is positive and presents agent sensitivity to the price changes. The difference in brackets reflects the trend and $\beta$ is the random term - IID normal random variable with mean zero and the constant standard deviation $\sigma^{\beta}$.

Fundamental analysis permits the difference between price and fundamental value for short time only. In long run there is an approximation of them. So if the price is below the fundamental value - the assets are bought and vice versa - the orders according fundamentalists are formalized:

$$
D_{t}^{F}=c\left(F_{t}-P_{t}\right)+\gamma_{t}
$$

The parameter $c$ is positive parameter and presents agent sensitivity to reaction. $F$ represents fundamental value - we keep as constant value to keep the implementation as simple as possible ${ }^{2} \cdot \gamma$ is the random term - IID normal random variable with mean zero and constant standard deviation $\sigma^{\gamma}$.

If we say that $N$ is the total number of agents and $K$ is the number of technical traders, then we define the weight of technical traders:

$$
W_{t}^{C}=K_{t} / N
$$

\footnotetext{
${ }^{1}$ independent and identically distributed.

2 in our implementation $\mathrm{F}=0$.
} 
and the weight of fundamental traders:

$$
W_{t}^{F}=\left(N-K_{t}\right) / N \text {. }
$$

Two traders meet at each step and they discuss about the success of their rules. If the second agent rules are more successful, the first one changes its behaviour with probability $K$. Probability of transition is defined as $(1-\delta)$. Also there is a small probability $\varepsilon$ that agent changes his mind independently. Transition probability is formalized as:

$$
\begin{aligned}
& K_{t}=\left(K_{t-1}+1\right) \text { with probability } p_{t-1}^{+}=\frac{N-K_{t-1}}{N}\left(\varepsilon+(1-\sigma)_{t-1}^{F \rightarrow C} \frac{K_{t-1}}{N-1}\right), \\
& K_{t}=\left(K_{t-1}-1\right) \text { with probability } p_{t-1}^{-}=\frac{K_{t-1}}{N}\left(\varepsilon+(1-\sigma)_{t-1}^{C \rightarrow F} \frac{N-K_{t-1}}{N-1}\right), \\
& K_{t}=K_{t-1} \text { with probability } 1-p_{t-1}^{+}-p_{t-1}^{-},
\end{aligned}
$$

where the probability that fundamental agent becomes technical one is:

$$
\begin{aligned}
& \left(1-\delta_{t-1}^{C \rightarrow F}\right)=0,5+\lambda \text { for } A_{t}^{C}>A_{t}^{F}, \\
& \left(1-\delta_{t-1}^{F \rightarrow C}\right)=0,5-\lambda \text { otherwise. }
\end{aligned}
$$

The probability that technical agent becomes fundamental one is:

$$
\begin{aligned}
& \left(1-\delta_{t-1}^{C \rightarrow F}\right)=0,5-\lambda \text { for } A_{t}^{C}>A_{t}^{F}, \\
& \left(1-\delta_{t-1}^{C \rightarrow F}\right)=0,5+\lambda \text { otherwise. }
\end{aligned}
$$

Success (fitness of the rule) is represented by past profitability of the rules that are formalized as:

$$
A_{t}^{C}=\left(\exp \left[P_{t}\right]-\exp \left[P_{t-1}\right]\right) D_{t-2}^{C}+d A_{t-1}^{C}
$$

for technical rules, and:

$$
A_{t}^{F}=\left(\exp \left[P_{t}\right]-\exp \left[P_{t-1}\right]\right) D_{t-2}^{F}+d A_{t-1}^{F}
$$

for the fundamental rules.

Agents use most recent performance (at the end of $A^{C}$ formula resp. $A^{F}$ ) and also the orders submitted in period $t-2$ are executed at prices started in period $t-1$. In this way the myoptic profits are calculated. Agents have memory - which is represented by the parameter $d$. Values are $0 \leq d \leq 1$. If $d=0$ then agent has no memory, much higher value is. Much higher influence has the profits on the rule fitness.

The implementation of this model was done in NetLogo development platform. The author of NetLogo is Uri Wilensky (Wilensky 1999). NetLogo is software platform for modelling problems or systems with natural or social character. Its deploying has started in 1999 and is still in progress in Centre for Connected Learning and Computer-Based Modelling in North-western University in Chicago (USA).

The tool is fully programmable. It is a variant of Logo language. The agent support can be added into the environment. The work with it is intuitive and easy. The language is 

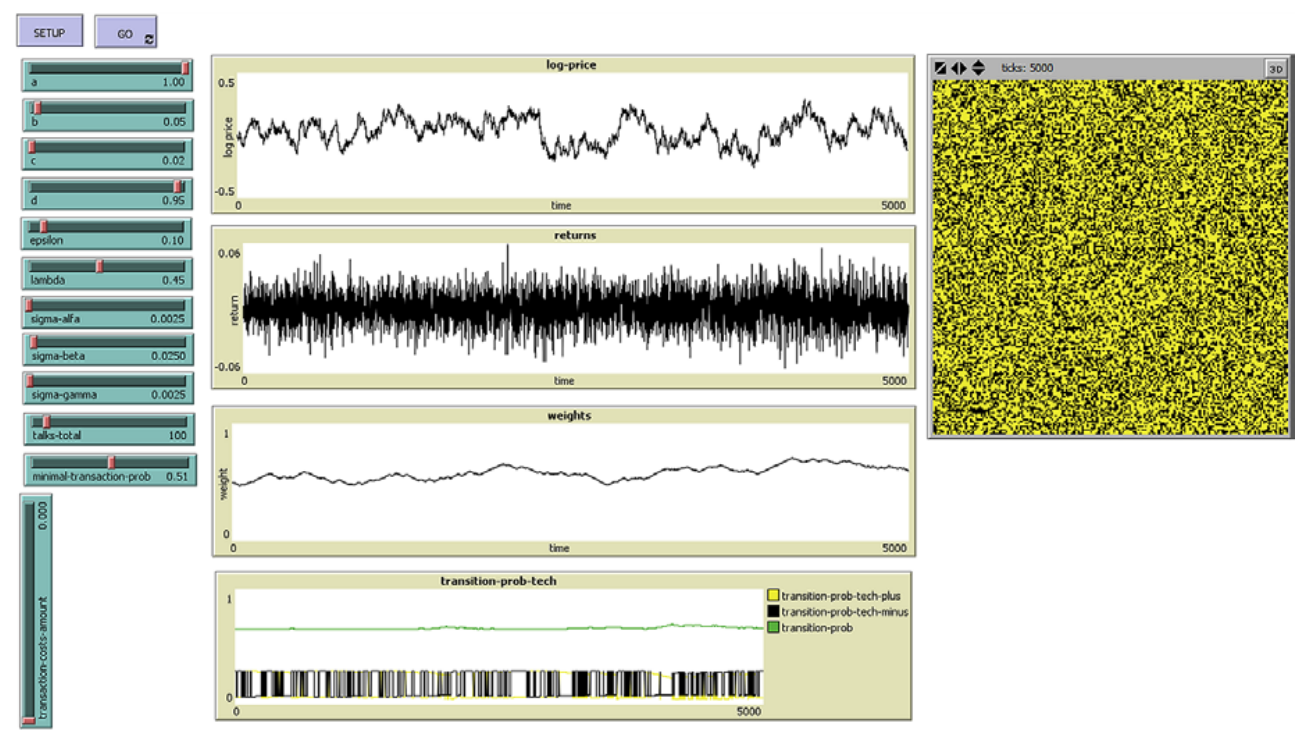

Fig. 1. Results of the simulation process (source: authors)

clear and simple. It provides the interface to develop various simulations and to visualize them. In Figure 1 it is possible to see the results of the simulation process. In the left part there are parameters (for values see the section 4). In the middle part of Figure 1 the evolution of key values (log price, returns as their changes, weights of technical traders) can be seen, and in the right part there is the rate between fundamental (black) and technical traders (yellow) shown in graphics. In the next section we explain the consequences of adding the transaction costs to the model.

\section{Transaction costs involvement into the model}

The aim of this paper is to investigate the influence of the transaction costs on the market stability (which is measured by the price volatility). Much more stable the market is, much less occur the price differences in a time. The entrance of transaction costs (TC) - e.g. a tax will have direct impact on the asset price. The model was changed to adopt this aspect into price formula. So the price is composed in this way:

$$
P_{t+1}=P_{t}+\alpha\left(W_{t}^{C} D_{t}^{C}+W_{t}^{F} D_{t}^{F}\right)+T C+\alpha_{t} .
$$

$T C$ is a value of the transaction costs. The value of $T C$ is constant during the simulation. While the tax is out-of trade factor, all the agents will be affected in the same way. Generally there can be also different kind of transaction costs than taxes - e.g. information obtaining costs. The TC increase has following results.

- The price increase will stimulate technical rules usage. The influence of the price increase on the expected future profit opportunities (as the fundamental value of the asset) is irrelevant, because they depend on the company state, rather than on the transaction costs. 
- In a short time, the price growth will attract technical traders. But after they realize profits their interests will fall down and the fundamental traders will start to dominate. That will lead to the financial market stabilization (price changes are falling - volatility of price is lower).

\section{Simulation results}

In this section we present practical results of the agent-based simulation implementation. Twenty simulations were processed. Averaged values are being plotted in the result graphs.

\subsection{Simulation in original model}

The parameterization of the model was kept from the original parameterization made by Westerhoff (Westerhoff 2009). The number of agents $(N)$ was set to 10,000 to obtain more relevant results. The parameters are:

$$
\begin{aligned}
& a=1, b=0.05, c=0.02, d=0.95, \lambda=0.45, \varepsilon=0.1, \\
& \sigma \alpha=0.0025, \sigma \beta=0.025, \text { and } \sigma \gamma=0.0025 .
\end{aligned}
$$

With these parameters the model is calibrated to the daily data. Number of turns, resp. time steps is 5000 days, which presents more than 13 and half of year. Westerhoff (Westerhoff 2009) found that growing number of agents reduces the model dynamicity and the volatility of price, while agents behaviour tends to be fundamental. This can be reduced by adding more communication turns. We have decided to give opportunity to talk to $1 \%$. This ensures positive influence on the model dynamicity.

In Figure 2 on the top left position the price values can be seen. Top right graph represents changes of the price in a time. The bottom left graph shows the weights of technical trading rules (in a long time there is a tendency to prefer fundamental than technical trading rules). Bottom right graph includes the distribution of returns (log price changes) compared with the normal distribution.

\subsection{Simulation with transaction costs}

In the next step we added TC to the model formalization. All the parameters are the same. Newly added TC is the constant value equal to 0.015 . From the following graphs in Figure 3 we can declare that transaction costs have the influence on the model. The price is growing in a short time, but in longer scope it is falling. The technical weights evolution is similar. In a short time it grows, but after it starts to fall - as the agents prefer the fundamental strategy. With higher number of fundamental traders the market stabilizes. This conclusion is readable from the returns (volatility of price changes is falling) in Figure 3.

\subsection{Simulation with higher transaction costs}

We achieved different results with the last set of simulations. All the parameters remained the same. Only the TC was doubled and became the constant value equal to 0.03 . Higher value of TC made the model destabilization, technical traders rules won 

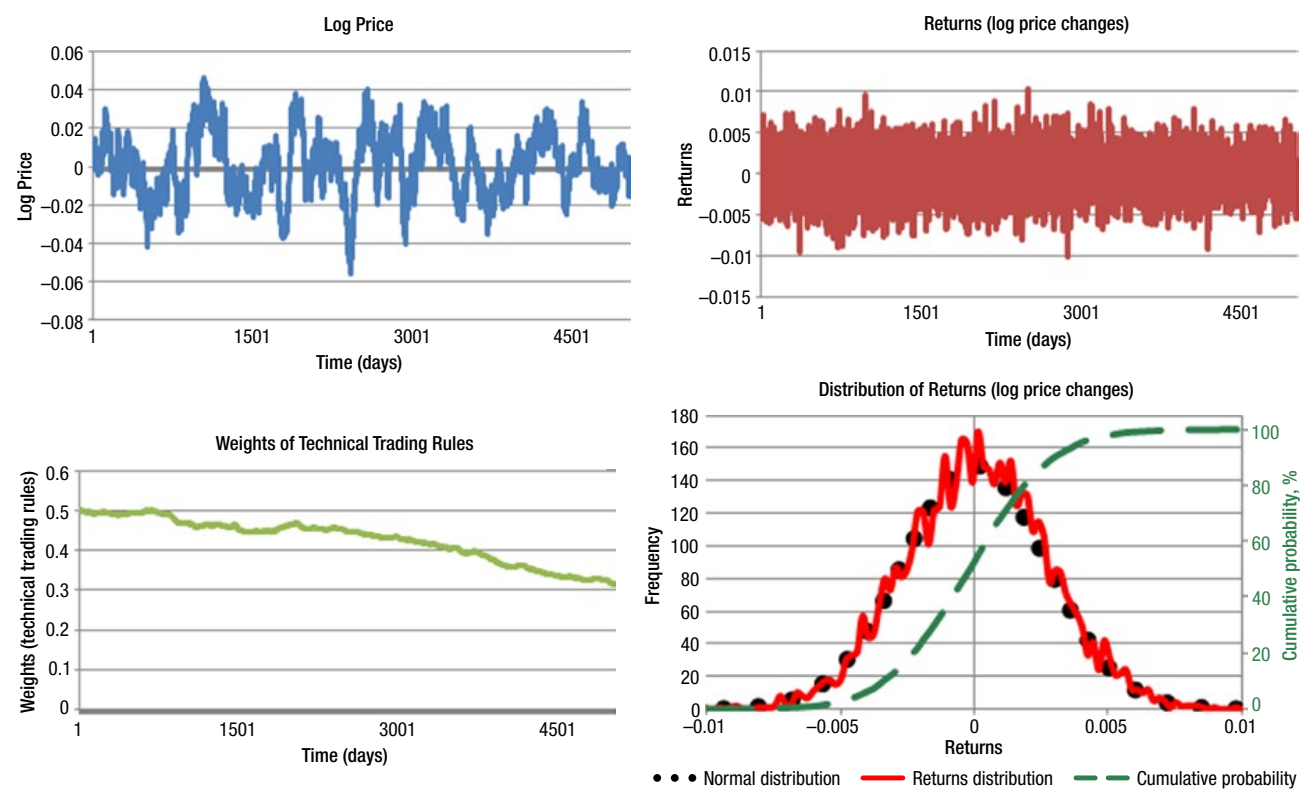

Fig. 2. Simulation results in original model (source: authors)
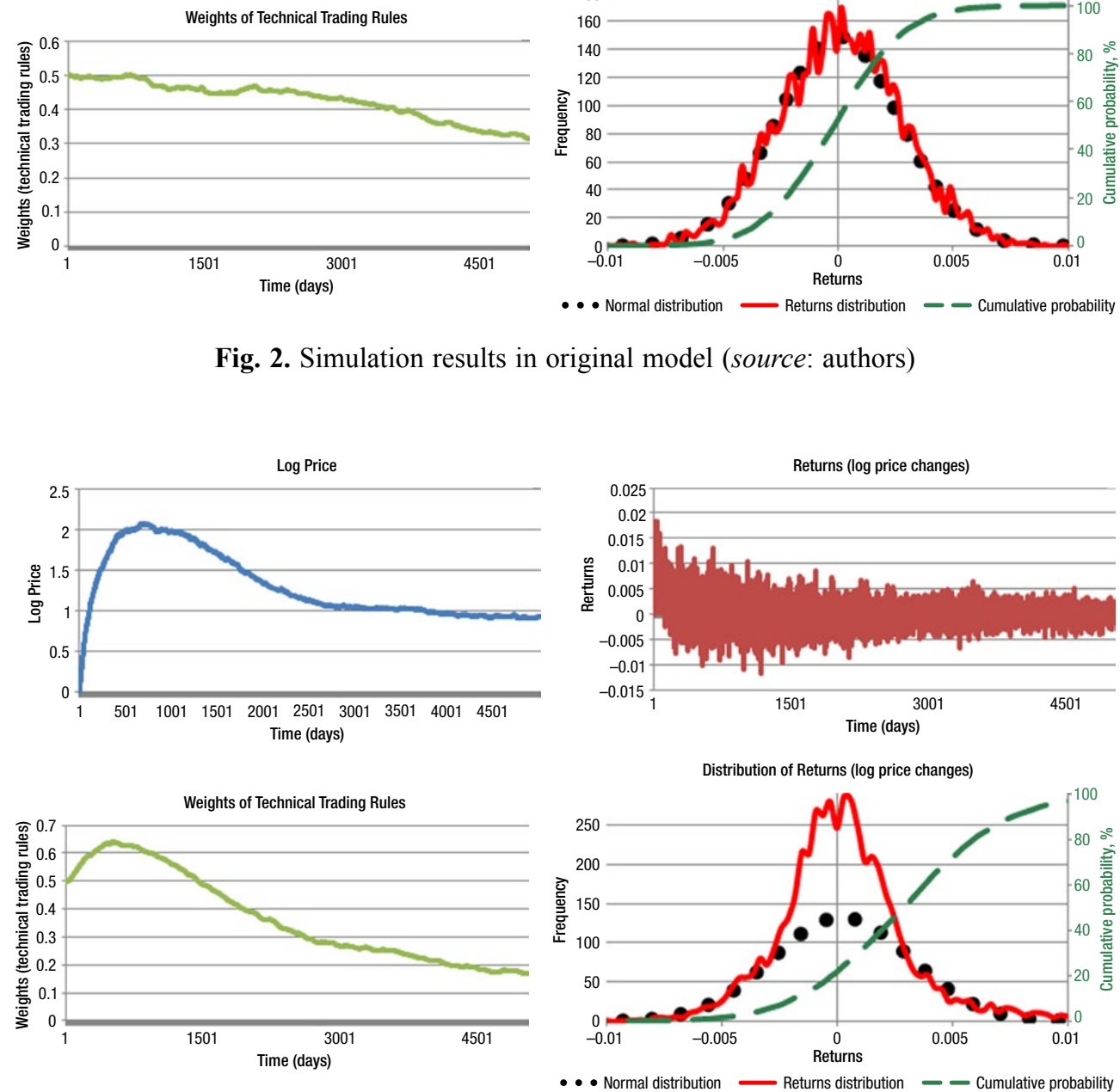

Fig. 3. Simulation results with transaction costs (source: authors)

(weight $=1$ ) and the price was growing without limit. Figure 4 demonstrates the contradictory effect on the market. Instead of the stabilization, the market started to be unstable. 

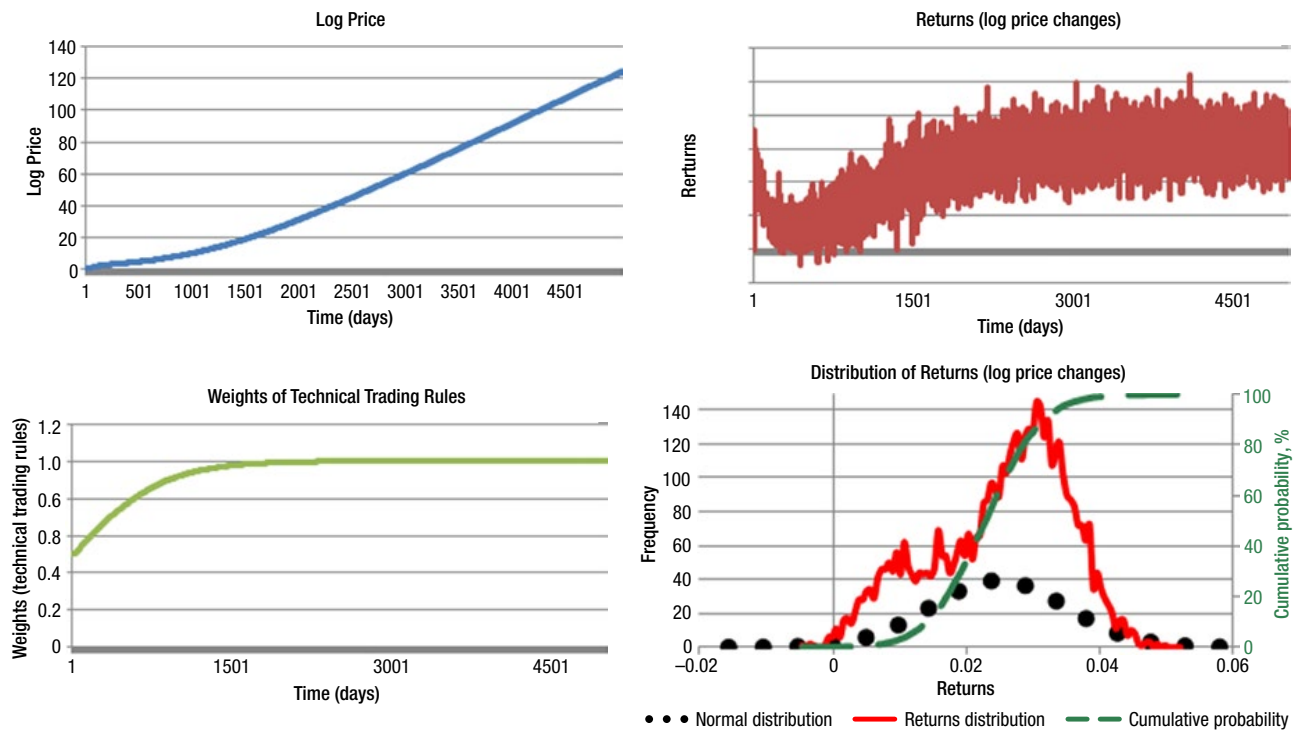

Fig. 4. Simulation results with higher transaction costs (source: authors)

\section{Conclusions}

The agent-based simulation of the financial model implemented in this paper has the tendency to stabilize itself in a long term, if the fundamental trading rules are overbearing the technical trading method. Although the bubbles and the crashes occur in our model, their tendencies are going to be less dangerous, because the price is targeting near the fundamental value and the volatility is going to be less. This description is similar to current situation on financial markets.

By adding transaction costs (Tobin tax) to the model we can observe price changes. In the first situation Tobin tax was defined to be equal to $1,5 \%$. The price grows up with the transaction costs to the bubble, while technical traders overtake the market. But the price starts to fall down according to the technical analysis growth. In this moment the volatility falls down and the market stabilizes. This is the main positive contribution of Tobin tax introduction into financial market in our agent-based simulation. On the other hand when the value of the transaction costs is disproportionately high ( $3 \%$ and higher), the system destabilizes and the price grows without limit.

This paper demonstrates positive impact of suitable transaction costs (Tobin tax) on the financial market stability in $\log$ run. The implementation of other agent-based simulations of financial market models could be the task for the future research. 


\section{References}

Allen, F.; Gale, D. 2002. Asset price bubbles and stock market interlinkages, in Federal Reserve Bank of Chicago and World Bank Groups Conference on "Asset Price Bubbles: Implications for Monetary, Regulatory, and International Policies", April 24-25, 2002, Chicago.

Brock, W.; Hommes, C. 1997. A rational route to randomness, Econometrica 65: 1059-1095. http://dx.doi.org/10.2307/2171879

Brock, W.; Hommes, C. 1998. Heterogeneous beliefs and routes to chaos in a simple asset pricing model, Journal of Economic Dynamics Control 22: 1235-1274.

http://dx.doi.org/10.1016/S0165-1889(98)00011-6

Burian, J. 2011. Multiagentní model transakčních nákladů na finančních trzích. VŠE Prague. [online], [cited 9 September 2011]. Available from Internet: http://www.eldar.cz/honza/articles/ burian ace fin market tc.doc

Farmer, J. D.; Foley, D. 2009. The economy needs agent-based modelling, Nature Opinion 460: 685-686 [online], [cited 9 September 2011]. Macmillan Publishers Limited. Available from Internet: http://www2.econ.iastate.edu/tesfatsi/EconomyNeedsABM.NatureAug2009.FarmerFoley.pdf.

Goncalves, C. P. 2011. Artificial financial market model, Netlogo Forum [online], [cited 9 September 2011]. Available from Internet: http://ccl.northwestern.edu/netlogo/models/community/ Artificial Financial Market Model

Habermeier, K.; Kirilenko, A. 2003. Securities transaction taxes and financial markets, IMF Staff Papers 50(Special Issue): 165-180.

Ho, L. I. 1998. Market crashes and informational avalanches, Review of Economic Studies 65(4): 741-760. http://dx.doi.org/10.1111/1467-937X.00066

James, Ch.; Smith, D. 2000. Are banks still special? New evidence on their role in the capitalraising process, Journal of Applied Corporate Finance 13: 52-63.

http://dx.doi.org/10.1111/j.1745-6622.2000.tb00041.x

Kirman, A. 1991. Epidemics of opinion and speculative bubbles in financial markets, in M.Taylor (Ed.). Money and financial markets. Oxford: Blackwell, 354-368.

Kirman, A. 1993. Ants, rationality, and recruitment, Quarterly Journal of Economics 108: 137156. http://dx.doi.org/10.2307/2118498

Lettau, M. 1997. Explaining the facts with adaptive agents: the case of mutual fund flows, Journal of Economic Dynamics and Control 21: 1117-1147.

http://dx.doi.org/10.1016/S0165-1889(97)00046-8

Lux, T. 1998. The socio-economic dynamics of speculative markets: interacting agents, chaos, and the fat tails of return distributions, Journal of Economic Behavior and Organization 33: 143-165. http://dx.doi.org/10.1016/S0167-2681(97)00088-7

Lux, T.; Marchesi, M. 1999. Scaling and criticality in a stochastich multi-agent model of a financial market, Nature 397: 498-500.

Macal, C. M.; North, M. J. 2006. Tutorial on agent-based modeling and simulation. Part 2. How to model with agents, in Proc. of the Winter Simulation Conference, 29 November, 2006, 79-83 [online], [cited 9 September 2011]. Available from Internet: http://www.informs-sim.org/ wsc06papers/008.pdf

Rutkauskas, A. V.; Ramanauskas, T. 2009. Building an artificial stock market populated by reinforcement learning agents, Journal of Business Economics and Management 10(4): 329-341. ISSN 1611-1699 (print), 2029-4433 (online).

Seely, A. 2012. The Tobin Tax: earlier debates. Standard Note SN/BT/1346, Business and Transport section. House of Commons Library.

Shleifer, A. 2000. Inneficient markets, an introduction to behavioral finance. Oxford: Oxford University Press. 
Siegel, J. J. 2003. What is asset price bubble? An operational definition, European Financial Management 9(1): 11-24. http://dx.doi.org/10.1111/1468-036X.00206

Situngkir, H.; Surya, Y. 2011. Agent-based model construction, Financial Economic System, vol. 1. [online], [cited 9 September 2011]. Bandung Fe Institute. Available from Internet: http:// cogprints.org/3767/1/hokky_new2004.pdf

Spišák, M.; Šperka, R. 2011. Financial market simulation based on intelligent agents - case study, Journal of Applied Economic Sciences 63(17): 249-256. ISSN 1843-6110 (print).

Spisak, M.; Sperka, R. 2012. Multi-agent simulation of financial market with transaction costs influence, Journal Scientific Papers of the University of Pardubice Series D. Czech Republic.

Stein, J. C. 1998. An adverse-selection model of bank asset and liability management with implications for the transmission of monetary policy, RAND Journal of Economics 29: 466-486. http://dx.doi.org/10.2307/2556100

Vymetal, D.; Sperka, R. 2011. Agent-based simulation in decision support systems, in Distance Learning, Simulation and Communication 2011, 10-11 May, 2011, Brno. ISBN 978-80-7231695-3.

Vymetal, D.; Slaninova, K.; Sperka, R.; Spisak, M. 2012. Output analysis in business process simulation, in Proc. of 7th International Symposium on business Administration: Creating a Caring Economics after the Global Economic and Financial Crisis: Theory, Research, and Practice, 11-12 May, 2012, Cannakale Onsekiz Mart University, Cannakale, Turkey. 10 p.

Westerhoff, F. 2009. A simple agent-based financial market model: direct interactions and comparisons of trading profits, BERG Working Paper Series on Government and Growth No. 61. Bamberg University.

Wilensky, U. 1999. NetLogo [online], [cited 9 September 2011]. Center for Connected Learning and Computer-Based Modeling, Northwestern University, Evanston, IL. Available from internet: http://ccl.northwestern.edu/netlogo

Wooldridge, M. 2009. An introduction to multiagent systems. 2nd ed. Chichester: John Wiley \& Sons Ltd. 461 p. ISBN 978-0-470-51946-2.

Yang, J. 1999. The efficiency of an artificial stock market. Economic Department, Concordia University. 44. p.

Roman ŠPERKA, Mgr. Ing. He is an assistent at the Silesian University in Opava, School of Business Administration in Karvina, Department of Informatics, Czech Republic, European Union. He completed his master degree (System Eingeneering and Informatics) in 2010 at the Silesian University, School of Business Administration in Karvina, Czech Republic. He completed his second master degree (Information systems) in 2011 at the University of Ostrava, Faculty of Sciences, Czech Republic. His research interests include multi-agent systems and their application in the field of economics, business and management. He is also interested in BPM, ABMS, business process modeling and simulation, and REA.

Marek SPIŠÁK, Ing. He is an assistent at the Silesian University in Opava, School of Business Administration in Karvina, Department of Informatics, Czech Republic, European Union. He completed his master degree (System Engineering and Informatics) in 2001 at the Silesian University, School of Business Administration in Karvina, Czech Republic. He is interested in multi-agent systems in the field of economics, business and management (especially in finance sector). Another field of interest are business processes - during the last 15 years he was participating on many Czech and international information systems projects (automotive, pharmacy, delicatessen, waste treatment) as programmer, system analyst and database designer. 